\title{
Effectiveness Of Yogic Practice On Respiratory Problems Among School Children In Selected Schools At Madurantakam, Kancheepuram Dt, Tamilnadu, India.
}

\author{
Dr.T.Komalavalli, M.Sc (N)., Ph.D \\ (Child Health Nursing, Karpaga Vinayaga College of Nursing/Tamilnadu Dr.M.G.R Medical \\ University, India)
}

\begin{abstract}
I have taken 100 samples from 10-12 years children towards Effectiveness of yogic practice on respiratory problems among school children in selected schools at Madurantakam and using Quantitative research approach, Quasi-experimental research design. In that the study suggested that the table (11.c) found $72 \%$ improvement in lung function, 68\% improvement is seen in manifestation of respiratory problems towards yogic practice due to the intervention program, viz., Yogic practice given by the researcher to the children of the present research.The study findings showed that the yogic practice was very effective in reducing the number of episodes as well as the prevention of respiratory problem and promoting/ improving the respiratory function of sample school children who had yogic practice and also the planned teaching program was very effective in improving knowledge as well as attitude towards yogic practice of sample children.
\end{abstract}

Keywords: Effectiveness, respiratory problems, school children, yogic practice

Submitted Date 28 June 2013

Accepted Date: 03 July 2013

\section{Introduction}

'Children are the priceless resources and any nation which neglects them would do so at peril' by Mahler

As we are entering into the $21^{\text {st }}$ century many aspects of our life remain the same as they were long before in the first century. The problem of child health and diseases have been with us for centuries especially in the developing countries like India where we have population explosion and lack of infrastructure[1]. Due to economic condition, heath of children is the most affected area which needs our immediate attentions. Children are tomorrow's adults. The 21 st century belongs to them and their children and grand children. They and their descendants are expected to be in good health by meeting the indicators as per Millennium development goals by the year 2015

Infections of the respiratory tract are perhaps the most common human ailment, being the source of discomfort as well. They are a substantial cause of morbidity and mortality among children. However in children, impaired respiratory tract reserves increase morbidity and mortality rates[2].

Respiratory disease is the term for disease of the respiratory system. These include disease of the lung, pleural cavity, bronchial tube, trachea, upper respiratory tract and of the nerves and muscles of breathing. Respiratory diseases range from mild and self-limiting such as the common cold to life threatening illness like bacterial pneumonia or pulmonary embolism[3]. They are common and important cause of illness and death. Hundreds of millions of people suffer worldwide from chronic respiratory diseases, 300 million people have asthma, and 210 million people have chronic obstructive pulmonary disease while millions of others suffer from other often undiagnosed chronic respiratory disease. These are silent killers if neglected and leading to death.

In developed countries, viruses, including respiratory syncytial virus, adenovirus, influenza virus and Para influenza virus, are the most common cause of respiratory infections. The distribution of viral pathogens differs depending on the population, geographic area and the socioeconomic levels [4].

As per the Base line report on Respiratory health, Green facts 2005, Respiratory diseases are a leading cause of mortality in developing countries, and one of the most common causes of illness in children of developed countries.

There are number of acute and chronic infections that can affect the lower respiratory tract. The two most common infections are bronchitis and pneumonia. Influenza affects both the upper and lower respiratory tracts. Antibiotics are often thought to be the first line treatment in lower respiratory tract infections[2]. However, these are not indicated in viral infections. It is important to use appropriate antibiotic selection based on the type of infections and the emerging resistance to conventional therapies.

Several studies reveal the practice of yoga reduce or prevent many diseases. One such disease is respiratory disease the awareness and measure of prevention of respiratory diseases to children if imparted the 
cause of consequence and effect of diseases will be controlled in later stage. Yoga practice is considered to be most effective practice can be followed by children and adults for prevention of many diseases and for well being.

Yoga can help people who suffer from these ailments by strengthening the body is immune system and opening the chest for easier breathing, which can help asthma and bronchitis patient. Other yoga breathing techniques can also help eliminate excess mucus from the body and help you breathe easier[5].

Yoga practices as a therapeutic programme is different from conventional medical practices. It aims to develop the resistance capacity in the individuals for various disturbances. Yoga can be a primitive oriented approach for health care as well as preventive method. Physical practices such as asana and pranayama can have tremendous influences in restoring the imbalance in the individuals. It is the Endeavour of this project to study the potentials of yoga practices on the children[6].

\section{Statement Of The Problem}

Effectiveness of yogic practice on respiratory problems among school children in selected schools at Madurantakam, Kancheepuram District, Tamilnadu.

\section{Objectives}

a) To assess the manifestations of respiratory problems among school children

b) To assess the lung restrictions among school children

c) To determine the relationship between the selected demographic characteristics and the intervention scores of school children on yogic practice on respiratory problems

\section{Research Hypotheses}

The following hypotheses stated for the present study:-

$\mathrm{H}_{1}$. There is significant difference in the manifestations of respiratory problems among sample children during pre and post yogic practice periods at $\mathrm{P}$ level $<0.05$

$\mathrm{H}_{2}$. There is significant difference in the lung restrictions among sample children between pre and post yogic practice periods at $\mathrm{P}$ level $<0.05$

$\mathrm{H}_{3}$. There is significant difference in the association between demographic characteristics and improvement scores of intervention program of the children at $\mathrm{P}$ level $<0.05$

\section{Assumption}

A. The yogic practice will improve the vital capacity of the lungs.

b. The yogic practice will minimize the episodes of manifestation of respiratory problems.

c. The yogic practice will reduce the complication of respiratory problems among children.

d. The yogic practice will improve the physiology of respiration in terms of vital lung capacity-
$>$ Forced vital capacity
$>$ Forced expiratory volume
$>$ Peak expiratory flow rate
$>$ Forced expiratory flow
$>$ Forced expiratory volume/forced vital capacity

\section{Delimitation Of The Study}

a) The study is delimited to the school children of Madurantakam town.

b) This study is conducted only to students in the age group of 10 and 12 years

c) The period of study is for one academic year.

d) Yogic practice is limited to certain selected asanas and pranayama

The conceptual frame work adopted for the study was based on general system model.

\subsection{Approach}

\section{Methodology}

A Quantitative research approach was followed.

\subsection{Research Design}

Quasi-experimental design 


\subsection{Setting}

The study was conducted in two schools namely, Vivekananda Matriculation School and Dr.Gengusamy Matriculation School located in Madurantakam Town, Kancheepuram district, Tamilnadu, and India.The schools consisted of two sections and had both boys and girls.

\subsection{Population}

The population of the study was the children among the age group 10-12 both male and female studying in the schools of Madurantakam Town.

\subsection{Criteria For Sample Selection}

7.5.1. Inclusion criteria

a) All the children were in the age group of 10 to 12 years in the selected schools at Madurantakam, Kancheepuram Dt.

b) Children, who were able to speak, read and write in English and Tamil.

\subsubsection{Exclusion criteria.}

a) School children above twelve years.

b) School children below ten years.

c) School children who are not willing to participate in this study.

d) School children with any other high risk condition of lungs.

e) School children on medication.

\subsection{Sample}

100 children in the age group of 10 to 12 years studying in VI, VII standard in the above mentioned two schools and who had satisfied the inclusion criteria, were selected on random basis.

\section{7. sampling techniques of the study}

Stratified random sampling technique was used for this study.

\subsection{Method Of Sample Selection}

Those who met the inclusion criteria were selected for this study. Boys and girls from two schools from VI, VII standard were selected. Each standard was considered as a stratum and from each stratum the students were selected by using stratified random sampling technique by using the attendance register number.

\subsection{Testing And Standardization Of The Tool}

A reliability analysis was done for the above tools and the co efficient was done. The split half method was used to test the reliability of alpha score for part $1=0.95$ and alpha part $2=0.96$ which proved that it was highly reliable.

\section{Pilot Study}

Pilot study was conducted to determine the feasibility of the main study and to require and modify the instrument. The study was conducted on 10 samples that satisfied the inclusion criteria. The tool was formed to be feasible, practicable and necessary changes were made after pilot study.

Necessary edition were made in the above tools taking the opinion of the expert in the field. Moreover content validity was also obtained from medical, nursing, yoga experts, and also from the general education. Thus the researcher ensured that valid tools were used for the research.

\section{Ethical Consideration Of The Present Study}

Consent was obtained from the principals of the schools. The researcher made arrangement to conduct yoga training and practice in separate session for female children. The parental acceptance for their child's practice was yet another crucial factor to be considered in the present study. Hence the investigator sent a circular to the parents of the subjects requesting their permission for these children to undergo yogic practice for a period of one month and follow up of six months. For the purpose of yogic practice and scientific measurements the investigator had chosen school as the site of the study. The facilities at school, availability of guidance from yoga experts and doctors for periodic consultations were the main reasons taken into consideration for selecting the above schools.

Official permission for data collection at above mentioned schools was obtained from the correspondent and principal. 
The permission letter was sent to subjects parents to get the details regarding parents consent. Baseline data with respect to parameter including height and weight, FVC, FEV1, PEFR, FEF, FVC/FEV1 had to be collected only from sample children. The subjects were informed about the date and time of the test to be conducted. All the subjects gathered in the school around 8 A.M. and were taken by bus in two consecutive days for baseline assessment.

\section{Data Analysis And Statistical Methods Used}

The data collected from the respondents were coded and entered in a personal computer. The data entered were thoroughly checked for the correctness of the entries. The data were analyzed using a widely used "statistical package "

\section{Manifestations Leading To Respiratory Problems}

The following table (11.a) indicates the inferential statistics of intervention scores for pre and post yogic practice of children

\begin{tabular}{|c|c|c|c|c|c|c|}
\hline \multirow{2}{*}{ ASPECTS } & \multicolumn{2}{|c|}{ PRE INTERVENTION } & \multicolumn{2}{|c|}{ POST INTERVENTION } & \multicolumn{2}{|c|}{ PAIRED t-Test } \\
\hline & MEAN & SD & MEAN & SD & VALUE & SIG. \\
\hline Manifestation of respiratory problems & 74.500 & 18.419 & 6.667 & 15.714 & 34.042 & 0.000 \\
\hline
\end{tabular}

Above table reveals that the mean value of presence of manifestation leading to respiratory problem among school children in the pre intervention period was 74.50 with standard deviation of 18.419 , and in the post intervention was 6.67 with standard deviation of 15.714. The scores in pre intervention mean value and standard deviation indicates that the children have more problems during pre-intervention period and the scores in post intervention mean value shows that there was reduced in manifestation to respiratory problems and improvement in respiratory health status after intervention programme. The paired t test value is 34.042 which is statistically highly significant improvement at $\mathrm{p}<0.001$ level.

Since the significance of the paired t-test is less than 0.05 , it is inferred that the scores are significantly different between pre and post intervention periods.It is concluded that the improvement is remarkably higher due to the intervention programme and it also indicates the effectiveness of the program offered by the researcher to the children.

The following table(11.b) displays the inferential statistics of lung function scores for pre and post yogic practice of sample children

\begin{tabular}{|l|l|l|l|l|l|l|}
\hline \multirow{2}{*}{ ASPECTS } & \multicolumn{2}{|l|}{ PRE INTERVENTION } & \multicolumn{2}{l|}{ POST INTERVENTION } & \multicolumn{2}{l|}{ PAIRED t-TEST } \\
\cline { 2 - 7 } & MEAN & SD & MEAN & SD & VALUE & SIG. \\
\hline $\begin{array}{l}\text { Assessment of lung restrictions } \\
\text { (PFT) among sample children }\end{array}$ & 81.000 & 22.451 & 8.800 & 15.909 & 26.640 & 0.000 \\
\hline
\end{tabular}

Above table reveals that the mean value of lung function among children during pre and post intervention programmes. In the pre intervention period the mean value was 81.000 with a standard deviation of 22.451, and in the post intervention period the mean value was 8.800 with a standard deviation of 15.91 .

From the mean values, it is evident that the children had more lung restrictions during pre intervention period. The mean value of scores in the post intervention program was very low which indicates that there was a drastic reduction in the lung restrictions after the intervention program. The paired $t$-test has been applied to assess whether the intervention program had any effect in improving the lung function measured using Spiro metric measurement.

The hypothesis assumed is that there is significant difference in lung function between the pre and post intervention scores. In other words, the intervention program does have any effect in improving the lung function assessed using Spiro metric measurement.

The paired t-test value is 26.640 -and the significance value is 0.000 . Since the significance value is less than 0.05 , the hypothesis has been accepted and it is concluded that the intervention does have an effect in improving the lung function. There is significant improvement in the lung function after the yoga practice given to the children.

The improvement scores for the aspects of manifestation and lung function are computed based on their improvement after the intervention program and the summary statistics are presented in the following table(11.c). 


\begin{tabular}{|c|c|c|c|c|c|}
\hline SCORES & MEAN & SD & IMPROVEMENT & $\begin{array}{l}\text { PAIRED } \mathrm{t} \quad- \\
\text { TEST }\end{array}$ & SIG. \\
\hline $\begin{array}{l}\text { Manifestation of respiratory } \\
\text { problems (Pre test) }\end{array}$ & 74.50 & 18.42 & \multirow{2}{*}{67.83} & \multirow{2}{*}{34.042} & \multirow{2}{*}{0.000} \\
\hline $\begin{array}{l}\text { Manifestation of respiratory } \\
\text { problems (Post test) }\end{array}$ & 6.67 & 15.71 & & & \\
\hline Lung restrictions (Pre test) & 81.00 & 22.45 & \multirow{2}{*}{72.20} & \multirow{2}{*}{26.640} & \multirow{2}{*}{0.000} \\
\hline Lung restrictions (Post test) & 8.80 & 15.91 & & & \\
\hline
\end{tabular}

From the above table, it is found that $72 \%$ improvement is found in lung function, $68 \%$ improvement is seen in manifestation of respiratory problems towards yogic practice due to the intervention program, viz., Yogic practice given by the researcher to the children of the present research.

It is evident from the current results Since the F test values are not statistically significance it is inferred that the improvements attained in all the five aspects are not influenced by the improvement of the children. In other words, a more variables of the children do not have any effect on improvement scores of children in any of the five aspects taken up in the current research

\section{Conclusion}

The study findings showed that the yogic practice was very effective in reducing the number of episodes as well as the prevention of respiratory problem and promoting/ improving the respiratory function of sample school children who had yogic practice and also the planned teaching program was very effective in improving knowledge as well as attitude towards yogic practice of sample children.

The above study has proved that respiratory problem can be prevented and the number of episodes reduced successfully through yogic practice. Hence the following suggestion / recommendation re made from the findings of the present study.

$>$ School curriculum should include yoga.

$>$ Every school should have regular practice in yoga.

$>$ Adequate govt. policy may be framed for govt. hospitals were victims of respiratory problem are reduced/treated to the through the yogic practice also.

$>$ Mass awareness program should be conducted in public places explaining the effect of yogic practice on preventing/ reducing.

$>$ The field of medical education and Para medical should accept or may be included on yogic practice as an instrument of alternate therapy to reduce the health related respiratory problem and promotion of the health behavior.

$>$ Protected water drainage system should be followed

$>$ Closed drainage system may be implemented in municipal town of Madurantakam.

$>$ Conducting in-service education program in medical and nursing field.

$>$ Similar study can be carried in preschool children

> Studies can be conducted to assess the effect of yoga in different diseases condition like hyper tension, diabetics, and emotional disorders and so on.

> Similar study may be conducted in high school children below 12 years of age and convent school children below 12 years and effects can be compared. A study can be done to assess the knowledge of the teachers and their attitude towards yogic practice.

$>$ Similar study may be conducted among nursing students and nurses.

\subsection{Nursing Practice}

\section{Nursing Implication}

School health education is an integral part of medical services. nurses can play an important role in health educational programs in helping the school children by teaching them regarding yogic practice on prevention of respiratory problem so that children will be prepared to face the problem in a positive manner .

\subsection{NURSING ADMINISTRATION}

Every primary health centre should be provide with adequate financial aid to provide medical care for respiratory problem adopting yogic practice

The school health nurse / public health nurse should periodically visit the school / community area and should involve in ongoing health education programme.

Every primary health centre may be providing with adequate medical experts with yogic practice to treat the patients with respiratory problem. 
Every local body may install one yogic centre where the common man can have an exposure to yogic practice and a kind of awareness in the benefits of yogic practice is created to common man also.

\subsection{NURSING EDUCATION}

The nursing curriculum of Indian schools and colleges give primary important to technical aspect of care rather than psychological aspects. Health personal make great mistakes by separating the body from the mind while treating the patients and tend to forget that, emotional arousal can exacerbate many physical conditions. Hence it is high time to include non-pharmacological technique like yoga practice in the nursing curriculum which equips the nursing students with the necessary skills in teaching the same. Moreover the nursing curriculum lays emphasis on pharmacological approach and gives very little attention to nonpharmacological measures, which has scope for independent practice. Nursing students often experience a Varity of stressors of away from home and environmental adjustment in the hostel, psychological fear of loneliness depression and other manifestation leads to respiratory problems like asthma are an important one yogic practice can be taught to the nursing students which function as a primary as well as secondary preventive measure.

\subsection{NURSING RESEARCH}

Professional organization in nursing are convinced of one important of nursing research as a major contribution to meeting the health and welfare needs of the patient. Aim of nursing research is to expand and broaden the scope of nursing. Nurses have no role in prescribing medicines. But her role in non pharmacological measures can be expanded which has scope for independent practice of yoga and it effect on different age group and disease control.

\footnotetext{
References

[1] Francis C.M. (1995), Health for all by 2000 AD.

[2] Terri kyle (2009), Essentials of Pediatric Nursing, $1^{\text {st }}$ edition, Lippincott Williams and wilkins publication, London

[3] Parthasarathi (2013), IAP Text book of Pediatrics, $5^{\text {th }}$ edition, Jaypee Brothers Medical Publishers, NewDelhi.

[4] Jane Ball, Bindler (2009), Pediatric Nursing, $1^{\text {st }}$ edition, Pearson education Publications, South Asia.

[5] Bhole M.V. and Karambedkar P.V. (1970), various yogic practices involving sub-atmospheric pressure changes, Yoga Mimansa.

[6] Dr.Asana Andiappen (2005), Ashtanga yoga a therapeutic approach to good health , Chennai, India.
} 